BACKGROUND: Both intestinal permeability and contractility are altered in inflammatory bowel disease. Little is known about their mutual relation. Therefore, an in vitro organ bath technique was developed to investigate the simultaneous effects of inflammation on permeability and smooth muscle contractility in different segments of the colon.

Methods and materials: BALB/c mice were exposed to a $10 \%$ dextran sulphate sodium drinking water solution for 7 days to induce a mild colitis, while control mice received normal tap water. Intestinal segments were placed in an oxygenated organ bath containing Krebs buffer. Permeability was measured by the transport of the marker molecules ${ }^{3} \mathrm{H}$-mannitol and ${ }^{14} \mathrm{C}$-polyethyleneglycol 4000 . Contractility was measured through a pressure sensor. Smooth muscle relaxation was obtained by salbutamol and $\mathrm{L}$ phenylephrine, whereas contraction was achieved by carbachol and 1-(3-chlorophenyl)-biguanide.

Results: The intensity of mucosal inflammation increased throughout the colon. Also, regional differences were observed in intestinal permeability. In both normal and inflamed distal colon segments, permeability was diminished compared with proximal colon segments and the non-inflamed ileum. Permeability in inflamed distal colon segments was significantly decreased compared with normal distal segments. Pharmacologically induced relaxation of smooth muscles did not affect this diminished permeability, although an increased motility positively affected permeability in inflamed and non-inflamed distal colon.

Conclusions: Inflammation and permeability is inversely related. The use of pro-kinetics could counteract this disturbed permeability and, in turn, could regulate the disturbed production of inflammatory mediators.

Key words: Dextran sulphate sodium, Mice, Inflammation, Intestinal permeability, Intestinal motility

\section{Effect of pharmacologically induced smooth muscle activation on permeability in murine colitis}

\author{
Freek J. Zijlstra ${ }^{1, C A}$, Marieke E. van Meeteren ${ }^{2}$, Ingrid \\ M. Garrelds ${ }^{3}$ and Maarten A.C. Meijssen ${ }^{4}$
}

${ }^{1}$ Department of Anesthesiology and ${ }^{3}$ Department of Pharmacology, Erasmus Medical Centre, P.O. Box. 2040, 3000 CA Rotterdam, The Netherlands; and ${ }^{2}$ Numico Research, Wageningen, The Netherlands; and ${ }^{4}$ Department of Gastroenterology, Medical Centre Haaglanden, The Netherlands

\author{
${ }^{\mathrm{CA}}$ Corresponding Author \\ Fax: +31 104633722 \\ E-mail: zijlstra@anes.azr.nl
}

\section{Introduction}

Human inflammatory bowel disease (IBD) represents Crohn's disease and ulcerative colitis. Despite extensive research, the aetiology of human IBD remains unclear. Genetic, environmental and immunologic factors are probably all involved in the pathogenesis of IBD. ${ }^{1-3}$

The gut wall of healthy subjects will normally provide both barrier and transport functions towards luminal molecules. In human IBD, an impaired barrier function has been observed. ${ }^{4-7}$ A defective barrier function increases the exposure of the mucosa to the gut contents, including bacteria and antigens, which may induce intestinal inflammation. It remains to be defined whether this defective barrier function occurs as the primary or secondary event, and which mechanisms and pathways are involved. ${ }^{8,9}$
In ulcerative colitis, altered gastrointestinal motility has been described. ${ }^{10,11}$ Several clinical studies have shown that ulcerative colitis patients have a decrease in motility, which may increase their diarrhoeal symptoms. ${ }^{10,11}$ According to Collins, ${ }^{12}$ studies in animal models clearly indicate a causal relationship between the presence of mucosal inflammation and altered sensory-motor function. Moreover, Snape and $\mathrm{KaO}^{10}$ observed that a decrease in colonic smooth muscle myoelectric and contractility response occurred in animals with experimental colitis. In 2,4,6trinitrobenzenesulphonic acid (TNBS)-induced colitis in rats, inflammation-induced changes in smooth muscle function were observed that might contribute to the abnormal motility associated with IBD. ${ }^{13}$

Information on the intestinal barrier function can be obtained by monitoring urinary excretion of orally administered test markers. Several intestinal perme- 
ability tests are operational in clinical practise and research.

Ideal intestinal permeability markers should be biochemically inert and cross the intestinal epithelium by non-mediated diffusion through defined pathways. ${ }^{14,15}$ Frequently used markers are the cylindrical polymer polyethylene glycol (PEG) 400 with a cross-sectional diameter of $5.3 \AA$, the globularshaped sugar alcohol mannitol with a cross-sectional diameter of $6.7 \AA$, and ${ }^{51} \mathrm{Cr}$-labeled ethylenediamine tetraacetic acid with a cross-sectional diameter of approximately $11 \AA .{ }^{16-18}$ Instead of PEG 400, which has a similar size as mannitol, PEG 4000 has also been used, with a cross-sectional diameter of more than 10 A.

The relation between colonic inflammation, inflammatory mediators, altered permeability and changed motility is not yet fully elucidated. Our aim was to investigate the effects of two different agonists on smooth muscle relaxation, namely salbutamol $\left(\beta_{2^{-}}\right.$ agonist), and 1-phenylephrine ( $\alpha_{1}$-agonist), and the effects of two different smooth muscle contracting agonists, namely carbachol (muscarinic receptor agonist) and 1-(3-chlorophenyl)-biguanide (5- $\mathrm{HT}_{3}$ agonist). Contractile activity and transmural permeability were measured simultaneously in an organ bath as described previously. ${ }^{19}$ The dextran sulphate sodium (DSS) model to induce a mild colitis in mice, as described by Okayasu et al., ${ }^{20}$ has been modified and extensively investigated as described previously. ${ }^{21-25}$

\section{Materials and methods}

\section{Animals}

The experiments were conducted with female adolescent BALB/c mice (20-22 g; IFFA Credo, France). Animals were kept individually on chopped wood bedding in polystyrene cages under a $12 \mathrm{~h}$ day/night cycle at $20-22^{\circ} \mathrm{C}$. Mice were permitted free access to a standard mouse chow (Hope Farms, Woerden, The Netherlands) and 10\% (w/v) DSS supplemented or normal tap water. The experiments were carried out after approval of the Ethics Committee for the use of experimental animals of the Erasmus university Medical Centre (protocol 118-00-02).

\section{Experimental design}

Mice received 10\% DSS (molecular weight $500 \mathrm{kDa}$, sulphur content $17 \pm 1 \%$; Pharmacia Biotech $\mathrm{AB}$, Uppsala, Sweden) added to their drinking water to induce colitis. Controls received normal tap water throughout the whole study. Animals were killed by cervical dislocation after drinking DSS for 7 days. Before sacrifice, mice were $20 \mathrm{~h}$ deprived from food.
Immediately after sacrifice, the intestinal segments were used for in vitro permeability and contractility experiments. The effect of smooth muscle relaxation and contraction, induced by various receptor agonists, on intestinal permeability was tested. In the first series of experiments, salbutamol and 1-(3-chlorophenyl)-biguanide were used to induce smooth muscle relaxation and contraction, respectively, while L-phenylephrine and carbachol were used for the same purpose in another series of experiments.

\section{Drugs}

Salbutamol (a specific $\beta_{2}$-adrenoceptor agonist, $10^{-2}$ M; generous gift of Glaxo Wellcome, UK), 1-(3chlorophenyl)-biguanide (a specific $5-\mathrm{HT}_{3}$ receptor agonist, $10^{-4} \mathrm{M}$; lot number 3067A, ICN, Aurora, OH, USA), L-phenylephrine (an $\alpha_{1}$-adrenoceptor agonist, $3 \times 10^{-4} \mathrm{M}$; lot number $115 \mathrm{H} 0665$, Sigma, St Louis, $\mathrm{MO}$, USA) and carbachol (a muscarine receptor agonist, $10^{-1} \mathrm{M}$; lot number $35 \mathrm{H} 2516$, Sigma) were used. All compounds were dissolved in distilled water and stored at $4^{\circ} \mathrm{C}$ until use.

\section{Tissue preparation}

After the mice were killed, the intestines were removed from the abdominal cavity. One segment of the ileum adjacent to the caecum, a proximal colon and a distal colon segment were taken and immediately immersed in standard Krebs buffer ( $\mathrm{pH} 7.4)$, containing $118 \mathrm{mM}$ of $\mathrm{NaCl}, 4.7 \mathrm{mM}$ of $\mathrm{KCl}, 2.5 \mathrm{mM}$ of $\mathrm{CaCl}_{2} \cdot 2 \mathrm{H}_{2} \mathrm{O}, 1.2 \mathrm{mM}$ of $\mathrm{MgSO}_{4} \cdot 7 \mathrm{H}_{2} \mathrm{O}, 1.2 \mathrm{mM}$ of $\mathrm{KH}_{2} \mathrm{PO}_{4}, 25 \mathrm{mM}$ of $\mathrm{NaHCO}_{3}$ and $8.3 \mathrm{mM}$ of glucose. The experimental ex vivo model used in this study has been described previously. ${ }^{19}$ In short, each end of an intestinal segment was directly cannulated with stainless-steel cannulas and mounted horizontally in a 5-ml double-walled Perspex organ bath. The organ baths, warmed to $37^{\circ} \mathrm{C}$ and filled with standard Krebs buffer, were continuously gassed with carbogen (95\% $\mathrm{O}_{2}$ and $5 \% \mathrm{CO}_{2}$ ). Next the intestinal lumen was filled with standard Krebs buffer, containing the marker molecules ${ }^{3} \mathrm{H}$-mannitol (NEN Life Science Products, Hoofddorp, The Netherlands) and ${ }^{14}$ C-PEG 4000 (Amersham Life Science, Hertogenbosch, The Netherlands); about 500,000 dpm/ml for each labelled marker. The distal cannula was connected to a lowpressure sensor (Dépex, De Bilt, The Netherlands), which measures the pressure difference between a passive port, set at $15 \mathrm{mmHg}$, and the active port. The signal was recorded by Multiple Channel Registration computer-software. The pressure detection range was $15 \pm 9 \mathrm{mmHg}$. 


\section{Permeability measurements in vitro}

Permeability measurements started at $t=0$ by replacing the organ bath fluid with $5 \mathrm{ml}$ of fresh, carbogenated Krebs buffer. Every $15 \mathrm{~min}, 2 \mathrm{ml}$ samples were taken in duplicate from the serosal reservoir for marker analysis, directly followed by exchange of the organ bath fluid. This procedure was continued for $60 \mathrm{~min}$. Samples were collected in 20$\mathrm{ml}$ Econo glass vials (Packard Instrument BV, Groningen, The Netherlands) and $8 \mathrm{ml}$ of scintillation fluid (Pico-Fluor 15; Packard Instrument BV) was added. Each vial was counted for radioactivity by a multi-channel $\beta$ liquid scintillation counter (1500 TRICARB Liquid Scintillation Analyser; Packard Instrument BV). The ${ }^{14} \mathrm{C}-\mathrm{PEG} 4000 /{ }^{3} \mathrm{H}$-mannitol $(\mathrm{P} / \mathrm{M})$ ratio was calculated at each time point and standardised with the $\mathrm{P} / \mathrm{M}$ ratio of the filling buffer at $t=0$ to perform statistical analysis. Due to the marked difference in molecular size between PEG 4000 and mannitol, a diminished $\mathrm{P} / \mathrm{M}$ ratio also means a diminished permeability.

\section{Contractility measurements in vitro}

Running parallel with the permeability measurements, contractility was monitored by measuring the intraluminal pressure $(\mathrm{mmHg})$ of each intestinal segment. At $t=0 \mathrm{~min}$, a control period started by the application of saline was monitored. At $t=15 \mathrm{~min}$, smooth muscle relaxation was induced in segments of controls and DSS-treated mice by adding a single dose of $50 \mu \mathrm{l}$ of salbutamol $\left(10^{-2} \mathrm{M}\right)$ to the organ bath directly after buffer exchange. At $t=30 \mathrm{~min}$, smooth muscle contraction was induced following the same procedure with a single dose of $50 \mu \mathrm{l}$ of 5 $\mathrm{HT}_{3}$ agonist (1-(3-chlorophenyl)-biguanide, $10^{-4} \mathrm{M}$ ). In an additional series of experiments, we tested contractility in the same way and at the same timepoints with single doses of $50 \mu \mathrm{l}$ of L-phenylephrine $\left(3 \times 10^{-4} \mathrm{M}\right)$ and $50 \mu \mathrm{l}$ of carbachol $\left(10^{-1} \mathrm{M}\right)$ to induce relaxation and contraction, respectively. After the experiment, the recordings of the intraluminal pressure were evaluated and intestinal contractility was expressed as the number of contractions per 15 min interval.

\section{Macroscopy and histology}

Upon sacrifice, the animal and the removed intestines were macroscopically examined. Signs of inflammation were scored in a blind fashion. The macroscopic score ranged from 0 to 12 , which represents the sum of scores for diarrhoea $(0=$ solid stool consistency, $1=$ semi-solid stool consistency, $2=$ watery stools), bloody stool $(0=$ none, $1=$ positive $)$, appearance of the skin $(0=$ shining, $1=$ dull, $2=$ hair loss $)$, locomotion $(0=$ lively, $1=$ languid $)$, colon colour $(0=$ pink, $1=$ light red, $2=$ dark red $)$, distension $(0=$ none, $1=$ distinctly), appearance of the colon $(0=$ normal, $1=$ thickened $)$ and weight gain $(0=>5 \%$, $1=0-5 \%, 2=$ weight loss).

Histological analysis was performed with pieces of the ileum and of the proximal and distal colon. The pieces were fixed in a $\mathrm{pH}$ 7-buffered 3.6\% formaldehyde solution (Lansberg-Rotterdam BV, Uden, The Netherlands) and embedded in paraffin wax. Sections cut at $5 \mu \mathrm{m}$ thickness and stained with haematoxylin and eosin were examined under a light microscope using a $250 \times$ magnification.

\section{Statistical analysis}

The data are presented as mean \pm standard error of the mean. The statistical significance was determined by non-parametric methods. $p<0.05$ was considered statistically significant.

\section{Results}

\section{DSS-induced inflammation}

After drinking a solution of $10 \%$ dextran sodium sulphate for 7 days, BALB/c mice developed clinical signs of colonic inflammation (Table 1). The overall macroscopic score in the DSS-treated mice was significantly increased compared with controls $(p<$ 0.001). This was mainly reflected by the occurrence of bloody stools, diarrhoea and weight loss. Bloody stools appeared in $83 \%$ of the DSS-exposed animals versus none of the controls and diarrhoea was present in $92 \%$ of the DSS-treated mice. In addition, during DSS exposure animals lost a considerable amount of weight, while controls slightly gained weight.

The degree of inflammation reflected by histology showed regional differences between the intestinal segments. The ileum was not affected by DSS, whereas aborally an increasing damage in inflamed colonic segments was observed.

\section{Intestinal contractility}

Recording of the intestinal motility resulted in expected contractility patterns in the control and inflamed segments of the small intestine and colon during pharmacological exposure (tracings not shown). Smooth muscle contractility was measured as the intraluminal pressure, while the agents were added at the serosal side of the intestinal segments to influence smooth muscle activity. Relaxation was registered as a pressure decline, and contraction as a pressure rise. In the intestinal segments of both control and DSS-treated mice, final concentrations of $3 \times 10^{-6} \mathrm{M}$ L-phenylephrine attenuated the smooth 
Table 1. Macroscopic degree of inflammation in DSS-induced colitis in mice

\begin{tabular}{lccccc}
\hline Group & $n$ & $\begin{array}{c}\text { Macroscopic score } \\
\text { (mean } \pm \text { SEM) }\end{array}$ & Bloody stools & Diarrhoea & $\begin{array}{c}\text { \% weight change } \\
\text { (mean } \pm \text { SEM) }\end{array}$ \\
\hline Control & 12 & $1.6 \pm 0.3$ & $0 / 12$ & $1 / 12$ & $+1.4 \pm 0.6$ \\
DSS & 12 & $6.5 \pm 0.4^{*}$ & $10 / 12^{*}$ & $11 / 12^{*}$ & $-13.6 \pm 1.8^{*}$ \\
\hline
\end{tabular}

muscle contractility, while addition of $10^{-3} \mathrm{M}$ carbachol induced strong contractions.

In an additional experiment, $10^{-4} \mathrm{M}$ salbutamol and $10^{-6} \mathrm{M}$ 1-(3-chlorophenyl)-biguanide were used with the same purpose. Salbutamol suppressed smooth muscle contractility whereas biguanide induced contractions (Table 2).

The exact amount of circular smooth muscle relaxation or constriction could not be derived from the pressure transducers. The intestinal activity of each segment, however, could be expressed as the number of spontaneous contractions during pharmacological exposure (Figs. 1 and 2, top panels). In the ileum, which served as the ultimate control, the frequency of contraction was low compared with the proximal and distal colon segments. An increased contractility was found in the presence of either carbachol or biguanide. No change in the frequency of contraction was observed in the inflamed colon compared with control segments during any pharmacological exposure. In the proximal colon of control mice, phenylephrine significantly reduced the number of contractions compared with the saline exposed time interval. Subsequently, carbachol exposure significantly increased the number of smooth muscle contractions.

\section{Intestinal permeability}

Simultaneously with contractility, the ex vivo permeability was measured from the luminal side towards serosal side of the intestinal wall with ${ }^{14} \mathrm{C}$-PEG 4000 and ${ }^{3} \mathrm{H}$-mannitol molecules. To reach the serosal side of the intestinal wall, both markers had to cross the epithelium, the lamina propria, and also the adjacent circular and longitudinal muscle layers of the muscularis externa and the serosa. Transmural permeation is expressed as the $\mathrm{P} / \mathrm{M}$ ratio of the large PEG 4000 and the small mannitol molecule (Figs. 1 and 2, bottom panels).

In the ileum, exposure to phenylephrine, carbachol, salbutamol and biguanide have no effects on the $\mathrm{P} / \mathrm{M}$ ratios both in controls and DSS-exposed mice. The $\mathrm{P} / \mathrm{M}$ ratio of the ileum segments, however, was higher compared with the proximal and distal colon segments as a result of a greater transport of mannitol in the colon.

In the inflamed distal colon, permeability was significantly decreased after both phenylephrineinduced relaxation and carbachol-induced contraction (Fig. 2, right bottom panel), compared with saline-exposed interval and control measurements (Fig. 3).

\section{Discussion}

Currently, several animal models are used in inflammatory bowel disease research. In 1990, Okayasu et $a l .^{20}$ developed a method to induce colitis in mice by the administration of DSS (MW $54 \mathrm{kDa}$ ) via their drinking water. The DSS model used in our study was adapted from this method. We used a DSS variant with a higher molecular mass $(500 \mathrm{kDa})$ and observed comparable macroscopic and histologic effects. DSS colitis is easily induced and the DSS model is known as a reproducible method in which colitis appears with changes corresponding well to those of human ulcerative colitis ${ }^{20,26}$. In our hands, administration of $10 \%$ DSS to BALB/c mice during 7 days induced a mild colitis. This was mainly reflected by the appearance of bloody stools, diarrhoea and weight loss. Histologic examination of the intestinal tissue showed a focal and superficial inflammation. An influx of inflammatory cells in the lamina propria and disturbed crypt architecture was observed in the colon, while the ileum was histologically not affected by DSS exposure.

In general, alterations in intestinal permeability are studied in flat tissue sheets mounted in Using chambers ${ }^{27}$ or with in vivo perfusion models, ${ }^{28}$ while alterations in contractility are mostly examined with tissue strips vertically mounted in organ baths. ${ }^{22,29}$ In the ex vivo method used for our study, permeability was monitored transmurally from the luminal towards the serosal side. Transmural permeability has

Table 2. Overview of contractile activities and number of movements of colonic segments induced by pharmacological intervention

\begin{tabular}{lcccc}
\hline & Salbutamol $\left(\beta_{2}\right)$ & Phenylephrine $\left(\alpha_{1}\right)$ & Carbachol (muscarine) & Biguanide $\left(5-\mathrm{HT}_{3}\right)$ \\
\hline $\begin{array}{l}\text { Contractility } \\
\text { Movements }\end{array}$ & Relaxation & Relaxation & Contraction & Contraction \\
& Decrease & Decrease & No effect/increase \\
\hline
\end{tabular}


Contractility controls

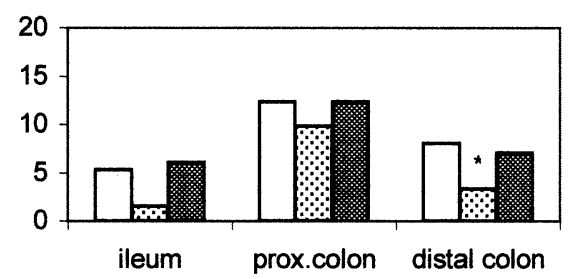

Permeability controls

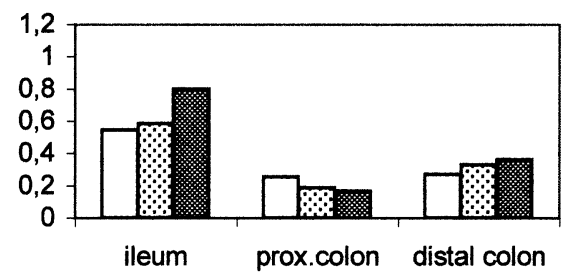

Contractility inflamed

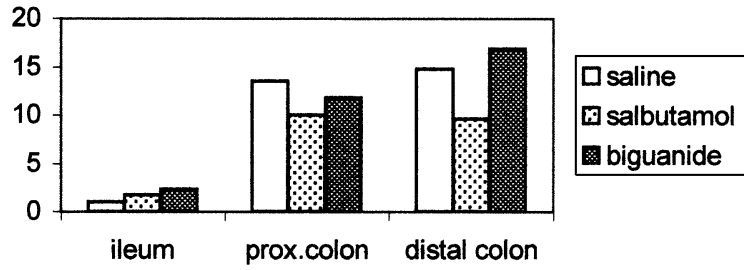

Permeability inflamed

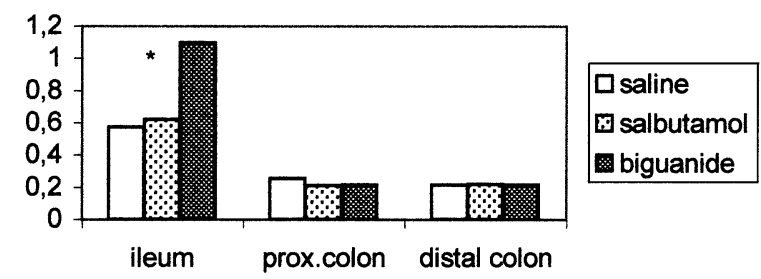

FIG. 1. Mean effects of salbutamol $\left(10^{-4} \mathrm{M}\right)$ and biguanide $\left(10^{-6} \mathrm{M}\right)$ on contractility measured as the number of movements in intestinal segments from the ileum, proximal colon and distal colon in control mice ( $n=6$; top left panel) and DSS-induced inflammation ( $n=6$; top right panel), and on permeability determined by the PEG $4000 /$ mannitol ratio in the same intestinal segments of control mice (bottom left panel) and DSS-induced inflammation (bottom right panel). ${ }^{*} p<0.05$ versus saline.

been described in the isolated everted sac model. ${ }^{30,31}$ Intestinal loops are everted and filled with fluid. In this method, the mucosal to serosal transport of permeability markers is measured to assess changes in the intestinal barrier function. In our model the intestinal segments are not everted, but directly filled with buffer containing the marker molecules. The large PEG 4000 molecule was used to mimic the macromolecular permeability of dietary antigens and bacterial products. Seidman et al. ${ }^{32}$ have shown that PEG 4000 is a suitable permeability marker, which is neither degraded by intestinal bacteria nor metabolised after absorption in the intestine. PEG 4000 and mannitol are both used as paracellular permeability probes. ${ }^{33,34}$ Large molecules like PEG 4000 are thought to diffuse via large pores at the crypt membrane, while the permeation pathway of small molecules can be both via small pores at the villus

\section{Contractility controls}

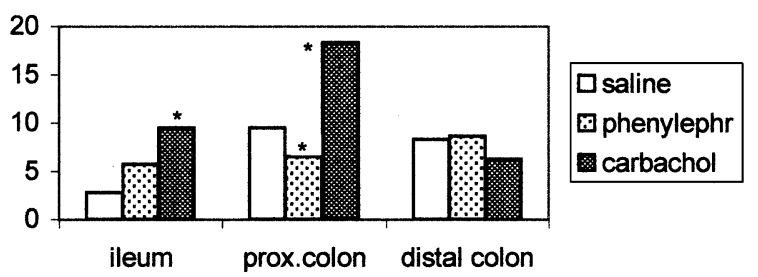

Permeability controls

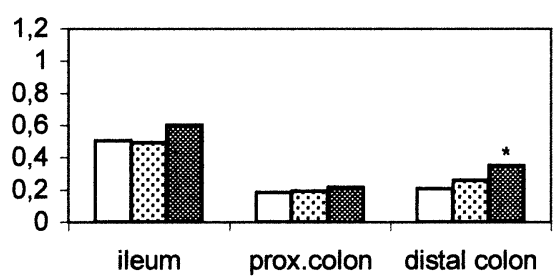

\section{Contractility inflamed}

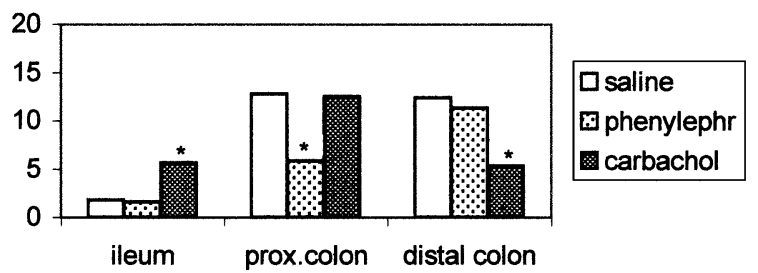

Permeability inflamed

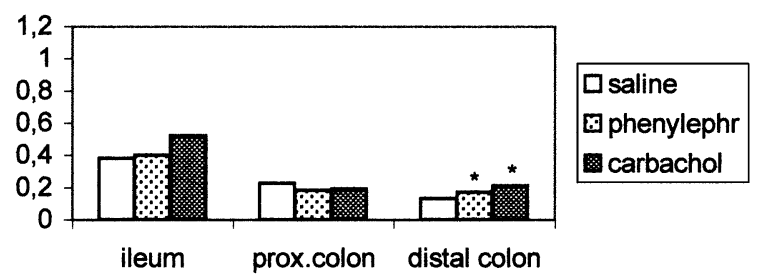

FIG. 2. Mean effects of phenylephrine $\left(3 \times 10^{-6} \mathrm{M}\right)$ and carbachol $\left(10^{-3} \mathrm{M}\right)$ on contractility measured as the number of movements in intestinal segments from the ileum, proximal colon and distal colon in control mice $(n=6$; top left panel) and DSS-induced inflammation ( $n=6$; top right panel), and on permeability determined by the PEG $4000 /$ mannitol ratio in the same intestinal segments of control mice (bottom left panel) and DSS-induced inflammation (bottom right panel). ${ }^{*} p<0.05$ versus saline. 


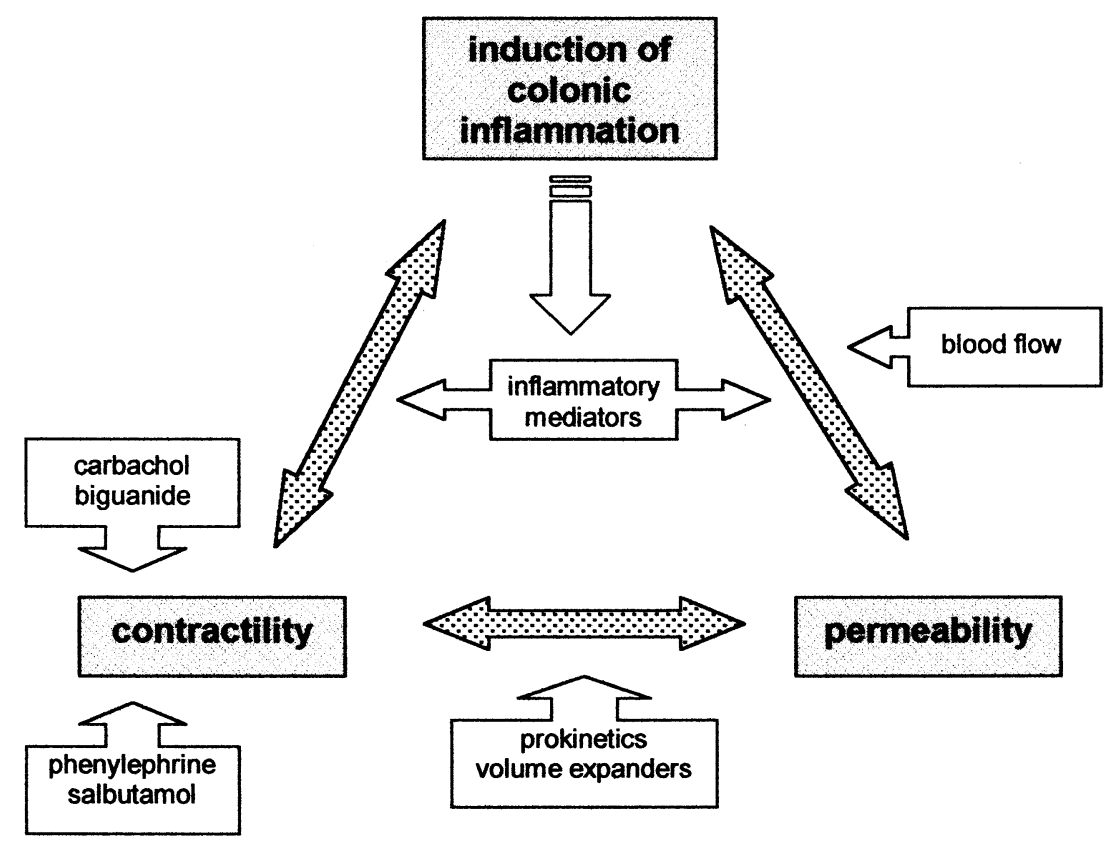

FIG. 3. Suggested interplay between colonic inflammation, contractile activity and permeability.

top or also at the larger pores of the crypt membrane. ${ }^{13,15}$ Thus, inflammatory damage of the intestinal barrier will result in an altered $\mathrm{P} / \mathrm{M}$ ratio. ${ }^{14}$

In the present study, a significantly decreased $\mathrm{P} / \mathrm{M}$ ratio was demonstrated in the inflamed distal colon compared with control. In the less inflamed proximal segment, permeability was not altered. Pharmacological-induced relaxation and contraction of smooth muscles had minor effects on permeability. Only a significant increase in permeability was observed after application of carbachol to both inflamed and control distal colon segments. In earlier studies we found an aboral increase of longitudinal smooth muscle contraction induced by carbachol in noninflamed colon, whereas this was abolished in inflamed colonic tissue. ${ }^{22}$ In the experimental setup of the herewith-used model, smooth muscle activity is mainly resulting from the circular instead of the longitudinal intestinal muscle layer. ${ }^{22}$ Although for all compounds used a clear relaxation or contraction was observed through registration of the intraluminal pressure, the frequency of contraction was less influenced by these agonists. In general, from our observations it could be concluded that pharmacologically induced reduction in motility, reflected by the number of movements, circular and longitudinal smooth muscle relaxations, does not directly alter intestinal permeability. On the other hand, the buildup pressure by constrictive agonists such as carbachol and biguanide slightly increased permeability in distal colon segments.

Intestinal permeability is not only influenced by the epithelial barrier, but also by the endothelial barrier. ${ }^{35}$ In our experimental set-up the latter pathway is not involved, however, as blood flow in the isolated intestinal segment is absent. Recently, we investigated intestinal blood flow in BALB/c mice by means of radioactive microspheres. ${ }^{36}$ Interestingly, there was a stepwise decline in the intestinal blood flow in control mice from the upper small intestine down to the distal colon. In DSS-induced inflammation, however, blood flow in the middle and distal colon was increased compared with control mice. Inflammatory mediators locally formed ${ }^{19,21,23,24}$ could be cleared more rapidly by an increased blood flow, considering systemic effects will be negligible. Attributive to this self-regulating effect, the additional use of pro-kinetics or volume expanders could be beneficial to counteract the disturbed permeability and, in turn, could regulate the influx and activation of inflammatory cells and the subsequent production of proinflammatory mediators, possibly resulting in a recovered colitis.

ACKNOWLEDGEMENTS. This study was performed by M.E.v.M. in the Department of Pharmacology, Erasmus Medical Centre, Rotterdam. Financial support was obtained from Gastrostart Foundation, Leiden, The Netherlands.

\section{References}

1. Russel MG, Stockbrugger RW. Epidemiology of inflammatory bowel disease: an update. Scand J Gastroenterol 1996; 31: 417-427.

2. Satsangi J, Welsh KI, Bunce M, Julier C, Farrant JM, Bell JL, Jewell DP. Contribution of genes of the major histocompatibility complex to susceptibility and disease phenotype in inflammatory bowel disease. Lancet 1996; 347: 1212-1217.

3. Fiocchi C. Inflammatory bowel disease: etiology and pathogenesis Gastroenterology 1998; 115: 182-205.

4. Bjarnason I, O'Morain C, Levi AJ, Peters TJ. Absorption of ${ }^{51} \mathrm{Cr}$-labelled ethylenediaminetetraacetate in inflammatory bowel disease. Gastroenterology 1983; 85: 318-322.

5. Munkholm P, Langholz E, Hollander D, Thornberg K, Orholm M, Katz $\mathrm{KD}$, Binder V. Intestinal permeability in patients with Crohn's disease and ulcerative colitis and their first degree relatives. Gut 1994; 35: 6872 . 
6. Nejdfors P, Wang Q, Ekelund M, et al. Increased colonic permeability in patients with ulcerative colitis: an in vitro study. Scand J Gastroenterol 1998; 33: 749-753.

7. Jenkins RT, Ramaga JK, Jones DB, Collins SM, Goodacre RL, Hunt RH. Small bowel and colonic permeability to ${ }^{51} \mathrm{Cr}$-EDTA in patients with active inflammatory bowel disease. Clin Invest Med 1988; 11: 151-155.

8. Nielsen OH, Rask-Madsen J. Mediators of inflammation in chronic inflammatory bowel disease. Scand J Gastroenterol Suppl 1996; 216 $149-159$.

9. Sanderson IR, Walker WA. Uptake and transport of macromolecules by the intestine: possible role in clinical disorders (an update). Gastroenterology 1993; 104: 622-639.

10. Snape Jr WJ, Kao HW. Role on inflammatory mediators in colonic smooth muscle function in ulcerative colitis. Dig Dis Sci 1988; 33: 65S$70 \mathrm{~S}$.

11. Reddy SN, Bazzocchi G, Chan S, et al. Colonic motility and transit in health and ulcerative colitis. Gastroenterology 1991; 101: 1289-1297.

12. Collins SM. The immunomodulation of enteric neuromuscular function implications for motility and inflammatory disorders. Gastroenterology 1996; 111: 1683-1699.

13. Hosseini JM, Goldhill JM, Bossone C, Pineiro, Carrero V, Shea-Donohue T. Progressive alterationbs in circular smooth muscle contractility in TNBS-induced colitis in rats. Neurogastroenterol Motil 1999; 11: $347-$ 356.

14. Travis S, Menzies I. Intestinal permeability: functional assessment and significance. Clin Sci 1992; 82: 471-488.

15. Bjarnason I, MacPherson A, Hollander D. Intestinal permeability: an overview. Gastroenterology 1995; 108: 1566-1581.

16. Katz KD, Hollander D, Vadheim CM, et al. Intestinal permeability in patients with Crohn's disease and their healthy relatives. Gastroenterology 1989; 97: 927-931.

17. Howden CW, Robertson C, Duncan A, Morris AJ, Russell RI. Comparison of different measurements of intestinal permeability in inflammatory bowel disease. Am J Gastroenterol 1991; 86: 1445-1449.

18. Hollander D. The intestinal permeability barrier. A hypothesis as to its regulation and involvement in Crohn's disease. Scand J Gastroenterol 1992; 27: 721-726.

19. Van Meeteren ME, van Bergeijk JD, van Dijk APM, Tak CJAM, Meijssen MAC, Zijlstra FJ. Intestinal permeability and contractility in murine colitis. Mediators Inflamm 1998; 7: 163-168.

20. Okayasu I, Hatakeyama S, Jamada M, Ohkusa T, Inagaki Y, Nakaya R. A novel method in the induction of reliable experimental acute and chronic ulcerative colitis in mice. Gastroenterology 1990; 98: 694-702.

21. Zijlstra FJ, van Dijk APM, Wilson JHP. Increased platelet activating factor synthesis in experimental colitis after diclofenac and 5-amino-salicylic acid. Eur J Pharmacol 1993; 249: R1-R2.

22. Van Bergeijk JD, van Westreenen H, Adhien P, Zijlstra FJ. Diminished nitroprusside-induced relaxation of inflamed colonic smooth muscle in mice. Mediat Inflamm 1998; 7: 283-287.
23. Van Dijk APM, Keuskamp ZJ, Wilson JHP, Zijlstra FJ. Sequential release of cytokines, lipid mediators and nitric oxide in experimental colitis. Mediat Inflamm 1995; 4: 186-190.

24. Zijlstra FJ, Garrelds IM, van Dijk APM, Wilson JHP. Experimental colitis in mice: effects of olsalazine on eicosanoid production in colonic tissue. Agents Actions 1992; 38: C76-C78.

25. Van Meeteren ME, Meijssen MA, Zijlstra FJ. The effect of dexamethasone treatment on murine colitis. Scand J Gastroenterol 2000; 35: 517-521.

26. Cooper HS, Murthy SN, Shah RS, Sedergran DJ. Clinicopathologic study of dextran sulphate sodium experimental murine colitis. Lab Invest 1993; 69: 238-249

27. Bijlsma PB, Peeters RA, Groot JA, Dekker PR, Taminiau JA, van der Meer R. Differential in vivo and in vitro intestinal permeability to lactulose and mannitol in animals and humans: a hypothesis. Gastroenterology 1995; 108: $687-696$

28. Krugliak P, Hollander D, Schaepfer CC, Nguyen H, Ma TY. Mechanisms and sites of mannitol permeability of small and large intestine in the rat. Dig Dis Sci 1994; 39: 796-801.

29. Myers BS, Dempsey DT, Yasar S, Martin JS, Parkman HP, Ryan JP. Acute experimental distal colitis alters colonic transit in rats. J Surg Res 1997; 69: $107-112$.

30. Nolan JP, Hare DK, McDevitt JJ, Ali MV. In vitro studies of intestinal endotoxin absorption. I. Kinetics of absorption in the isolated everted gut sac. Gastroenterology 1977; 72: 434-439.

31. Yamamoto A, Utsumi E, Sakane T, Hamaura T, Nakamura J, Hashida M, Sezaki H. Immunological control of drug absorption from the gastrointestinal tract: the mechanism whereby intestinal anaphylaxis interferes with the intestinal absorption of bromthymol blue in the rat. $J$ Pharm Pharmacol 1986; 38: 357-362.

32. Seidman EG, Hanson DG, Walker WA. Increased permeability to polyethylene glycol 4000 in rabbits with experimental colitis. Gastroenterology 1986; 90: 120-126.

33. Mullin JM, Marano CW, Laughin KV, Nuciglio M, Stevenson BR, Soler P. Different size limitations for increased transepithelial paracellular solute flux across phorbol ester and tumor necrosis factor-treated epithelial sheets. J Cell Physiol 1997; 171: 226-233.

34. Ameno H, Tani T, Hanasawa K, Kodama M. New method for the detection of bacterial translocation using intestinal permeability with polyethylene glycol 4000. Eur Surg Res 2000; 32: 23-29.

35. Sun Z, Wang X, Andersson R. Role of intestinal permeability in monitoring mucosal barrier function. History, methodology, and significance of pathophysiology. Dig Surg 1998; 15: 386-397.

36. Garrelds IM, Heiligers JPC, van Meeteren ME, Duncker DJ, Saxena PR, Meijssen MAC, Ziilstra FJ. Intestinal blood flow in murine colitis induced with dextran sulfate sodium. Dig Dis Sci 2002; 47: 2231-2236.

Received 22 November 2002

Accepted 3 December 2002 


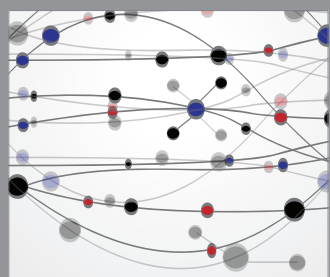

The Scientific World Journal
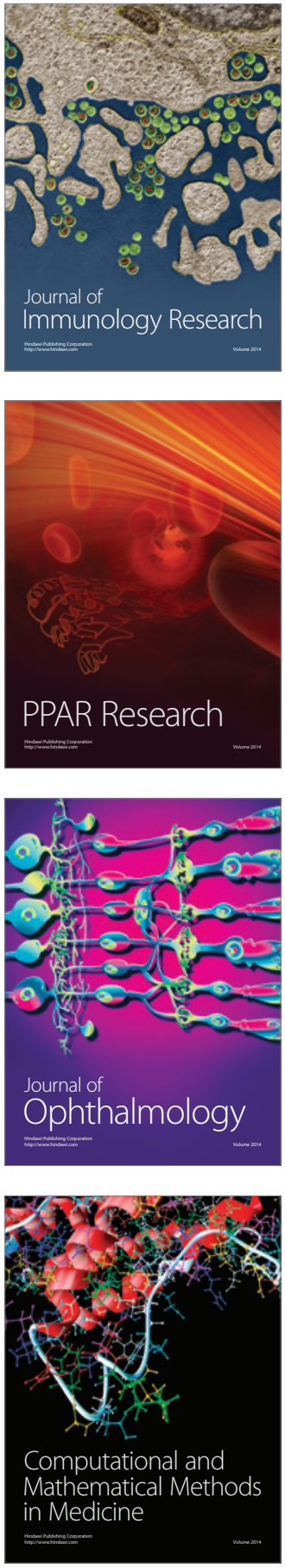

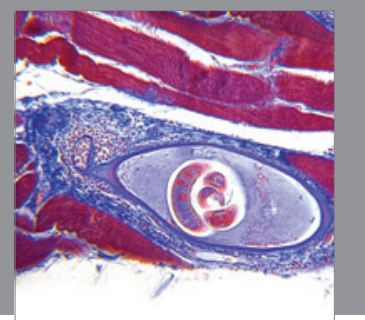

Gastroenterology

Research and Practice
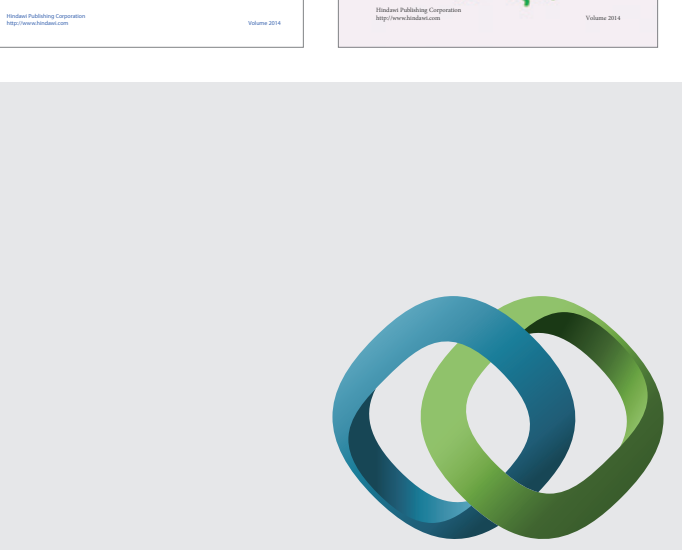

\section{Hindawi}

Submit your manuscripts at

http://www.hindawi.com
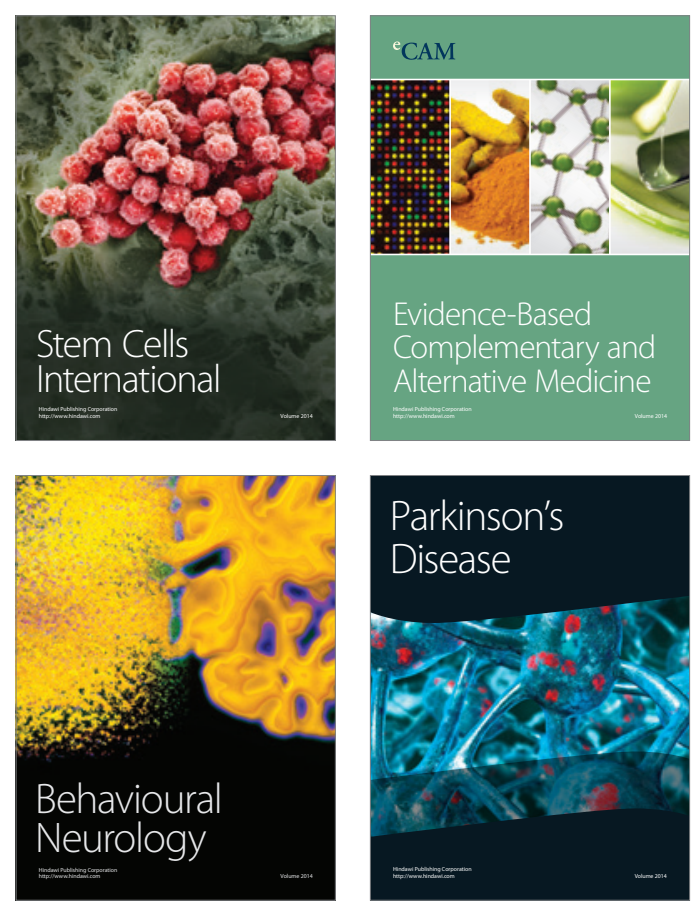

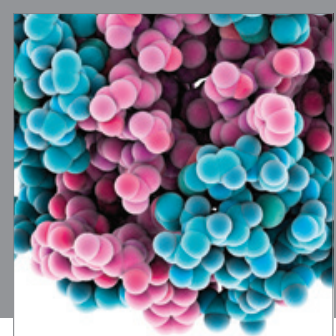

Journal of
Diabetes Research

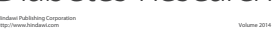

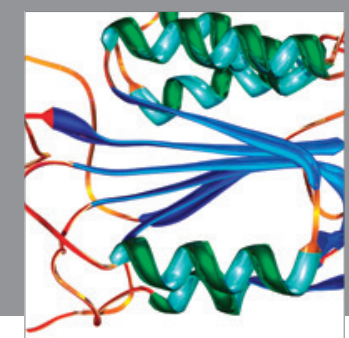

Disease Markers
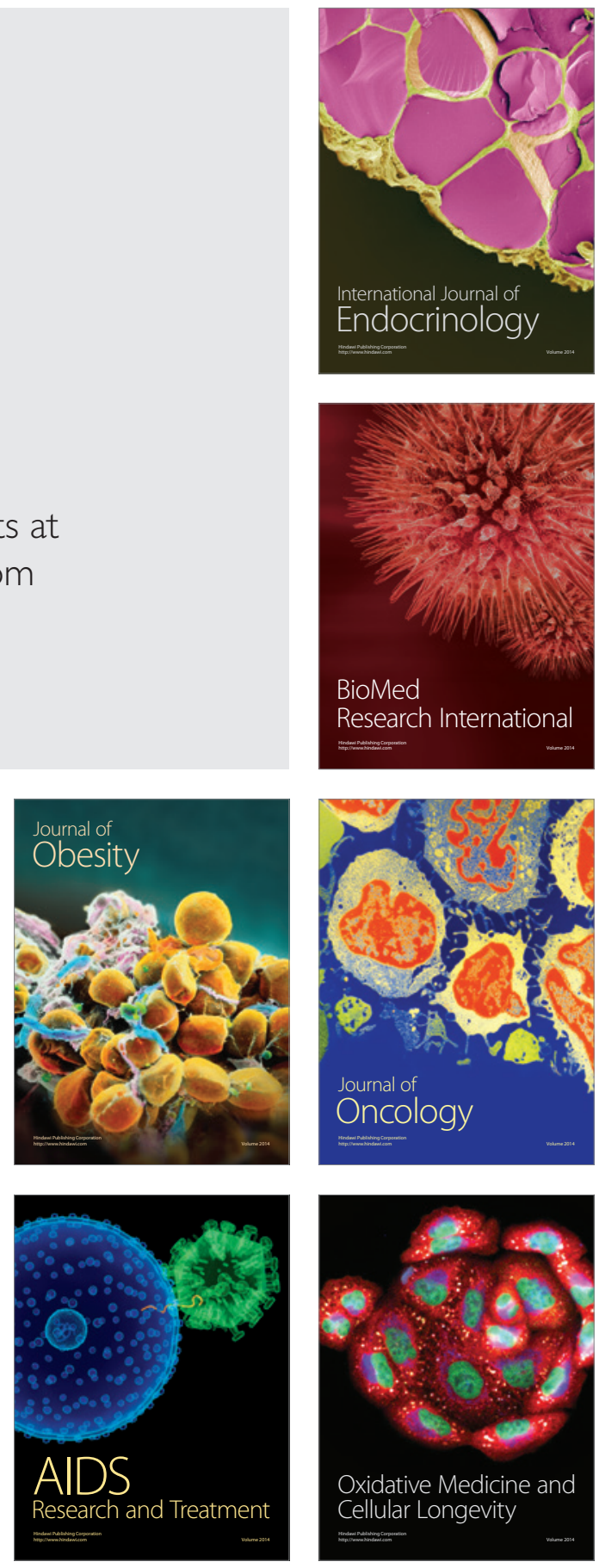